Volume 7, No. 12 December 2019

International Journal of Emerging Trends in Engineering Research

Available Online at http://www.warse.org/IJETER/static/pdf/file/ijeter187122019.pdf

https://doi.org/10.30534/ijeter/2019/187122019

\title{
Noncoaxial Two-Shaft Six-Speed Gearboxes
}

\author{
Vladimir Ivanovich Nekrasov ${ }^{1}$, Ruslan Albertovich Ziganshin ${ }^{2}$, Anna Vladimirovna Ziganshina ${ }^{3}$, Nikolay \\ Stepanovich Zakharov ${ }^{4}$ \\ ${ }^{1}$ Tyumen industrial University, Branch Office in Surgut, Russia \\ ${ }^{2}$ Tyumen industrial University, Branch Office in Surgut, Russia \\ ${ }^{3}$ Tyumen industrial University, Branch Office in Surgut, Russia \\ ${ }^{4}$ Tyumen industrial University, Branch Office in Surgut, Russia
}

\begin{abstract}
This article discusses possibilities of extension of components and operational performances of land vehicles by means of improvement of transmission designs. Specifications of vehicle transmissions equipped with two-shaft six-speed gearboxes are analyzed. Gear ratios $U$ as a function of gear numbers $N$ are plotted and mathematical models of statistically average and improved six-speed gearboxes are developed. Kinematic flowcharts of statistically average and improved two-shaft six-speed gearboxes are presented as well as kinematic flowchart of improved gearbox with two clutches. Operation of improved two-shaft six-speed gearbox is described. Technical and economical evaluation of improved gearboxes is given.
\end{abstract}

Key words: gearbox, transmission, gear ratio, kinematics, design.

\section{INTRODUCTION}

Six-speed two-shaft gearboxes (GBs) are widely applied in car manufacturing. Such GBs are used for vehicles with lateral engine position, this variant is inexpensive and simple. Such design is preferred by most car manufacturers. The advantage of two-shaft six-speed GB is obvious: it occupies small space, hence, it is possible to install larger and more powerful motors under the hood. The main advantages of two-shaft GBs are as follows: relatively simple design, low weight, high efficiency upon torque transformation by one pair contact.

\section{METHODS}

\subsection{Analysis of specifications of transmissions equipped with two-shaft six-speed GBs}

The specifications of some vehicles equipped with two-shaft six-speed GBs as well as of their transmissions are summarized in Table 1, the data were collected and analyzed for 160 vehicles. The main transmission parameters are given: $U_{0}$ is the gear ratio of main transmission; $\mathrm{U}_{\mathrm{GB}}$ is the gear ratios of $\mathrm{GB}$; $\mathrm{U}_{\mathrm{tr}}$ is the gear ratios of transmission; $D$ is the range, gear ratios of low to top gears; $\mathrm{q}_{\text {avg }}$ is the average interval, averaged ratios of adjacent gears; $\Delta \mathrm{q}$ is the difference between intervals of adjacent gears. Transmission type: $\mathrm{M}$ - mechanic, A - automatic.

The number of GB gears and their sizes influence significantly dimensions and metal intensity of the assemblies. Maximum gear ratio of a gear pair is usually in the range of $3.45 \div 4.2$ in order to limit reasonably inter-axial distance and sizes of GB (see table, No. 6: $\mathrm{D}=$ $4.61 ; \mathrm{q}=1.36 ; \Delta \mathrm{q}_{\max }=0.17 ; \mathrm{U}_{\mathrm{GB} 1}=3.78 ;$ No. $9: \mathrm{D}=6.09 ; \mathrm{q}=1.44$; $\Delta \mathrm{q}_{\max }=0.21 ; \mathrm{U}_{\mathrm{GB} 1}=4.2$ ). Increase in amount of gears and range of two-shaft GBs together with limitation of maximum gear ratio of gear pair leads to necessity of multiplying gears and retention of high gear ratio in main gear. For instance, modern six-speed two-shaft GBs operate with two-three multiplying gears, and $\mathrm{U}_{\mathrm{o}}$ reaches 4.44 (No. 8, see table). For the considered 160 vehicles, $D=4.61 \div 6.09 ; \mathrm{q}$ $=1.36 \div 1.44 ; \Delta \mathrm{q}_{\max }=0.16 \div 0.31$. The intervals for top gears are reduced for convenient gear shifting. 
Vladimir Ivanovich Nekrasov et al., International Journal of Emerging Trends in Engineering Research, 7(12), December 2019,836 - 841

Table 1: Specifications of vehicles and their six-speed transmissions

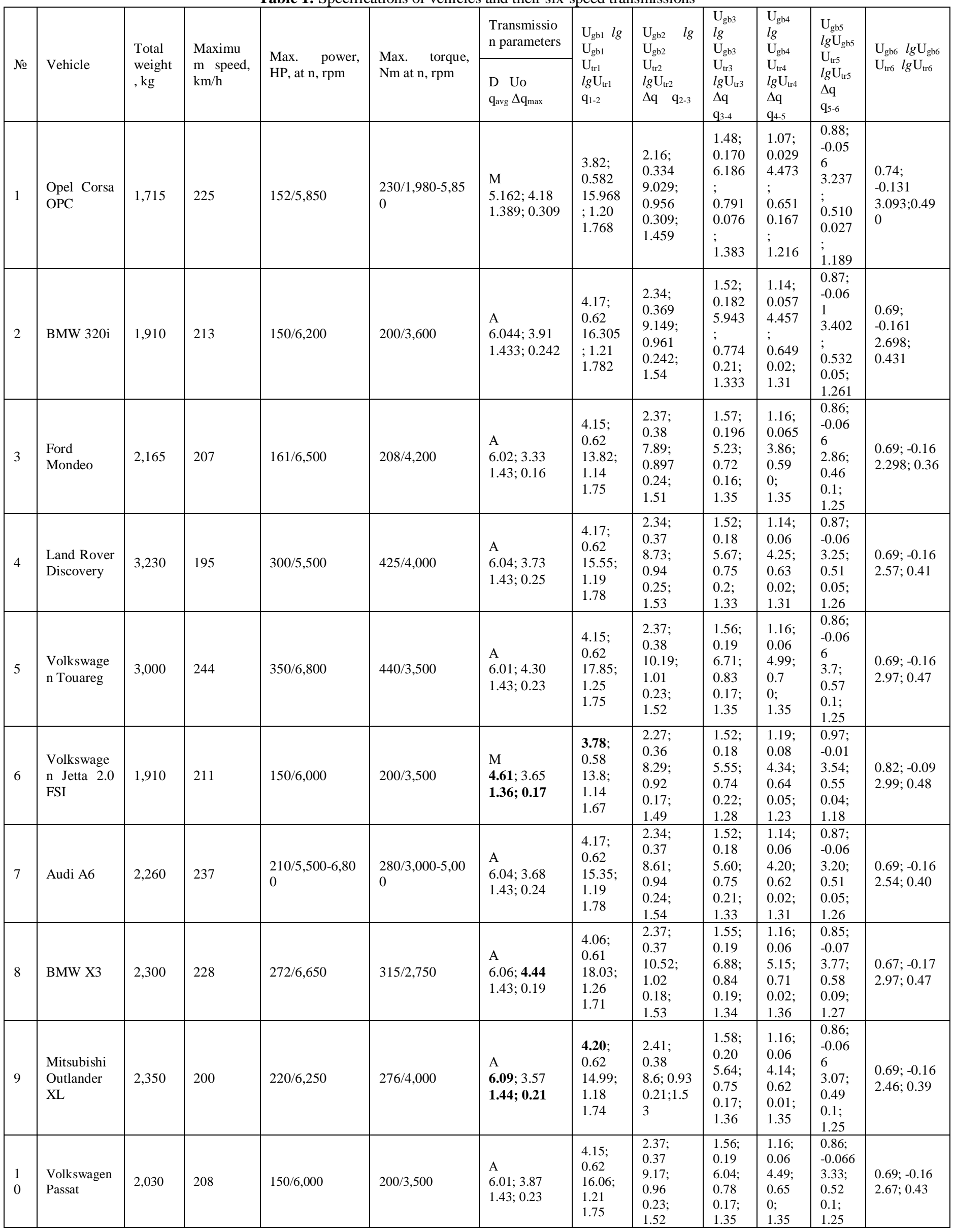


On the basis of data in Table 1 , the gear ratios $U$ were plotted as a function of gear number $\mathrm{N}$ and mathematical model of statistically average six-speed GB was developed. Figure 1 illustrates flattened curves of gear ratios $U$ as a function of gear number $N$ for statistically average GB (Fig. 2) and IGB (improved GB) (Fig. 3) in semi-logarithmic coordinates. These curves are described by the exponential function: $y=a e^{b x}$, where $e=2.718 ; a$ and $b$ are the coefficients; $x$ is the gear number of GB. Dependence for statistically average GB is determined by the equation: $y=4,721 e^{-0.335 x}$ (the determination coefficient $\left.\mathrm{R}^{2}=0.9683\right)$, and for IGB: $y=9.8984 e^{-0.4171 x}\left(\mathrm{R}^{2}=1\right)$.

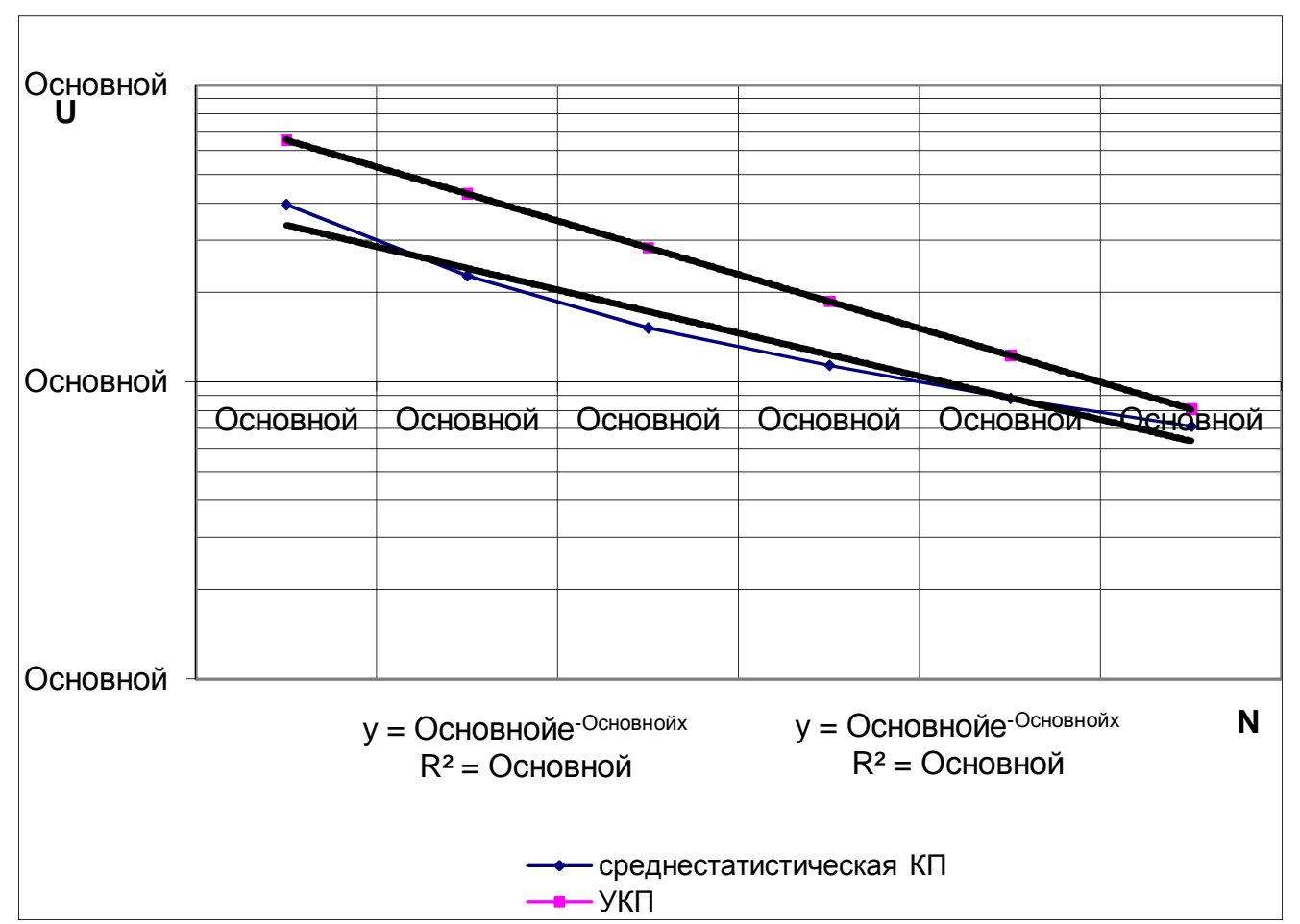

Figure 1: Gear ratios $U$ as a function of gear number N (1-6) of six-speed statistically average GB and IGB

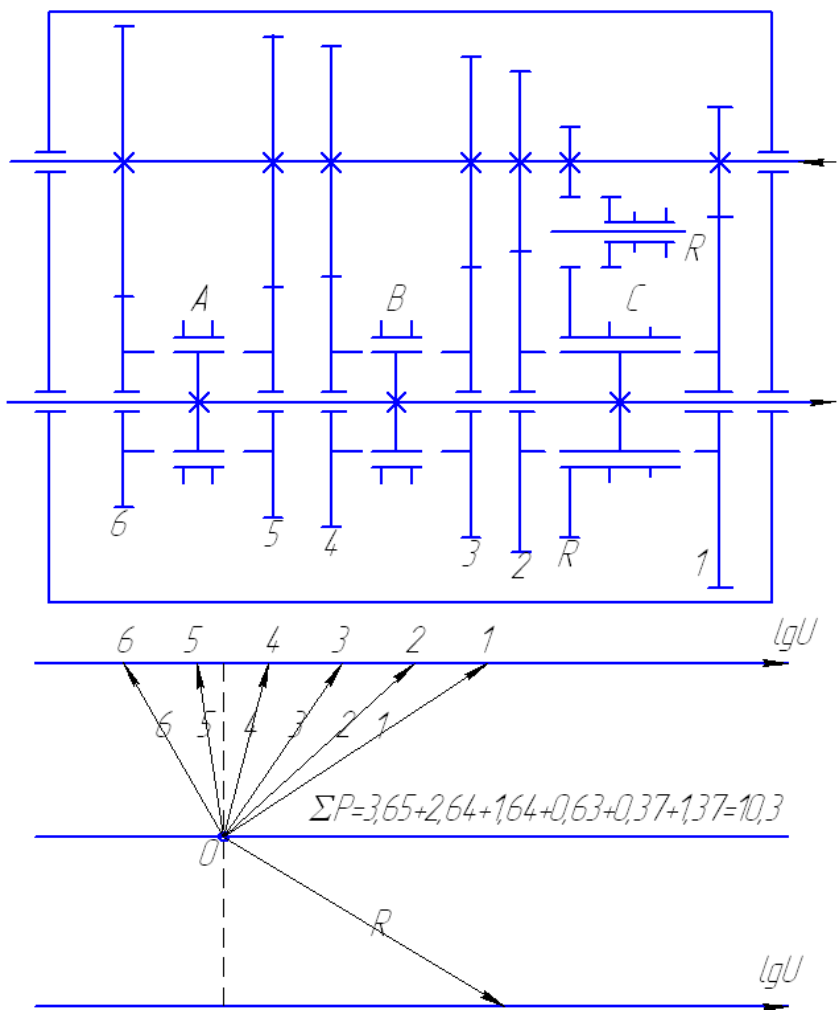

Figure 2: Kinematic flowchart and ray path diagram of statistically average two-shaft six-speed GB 

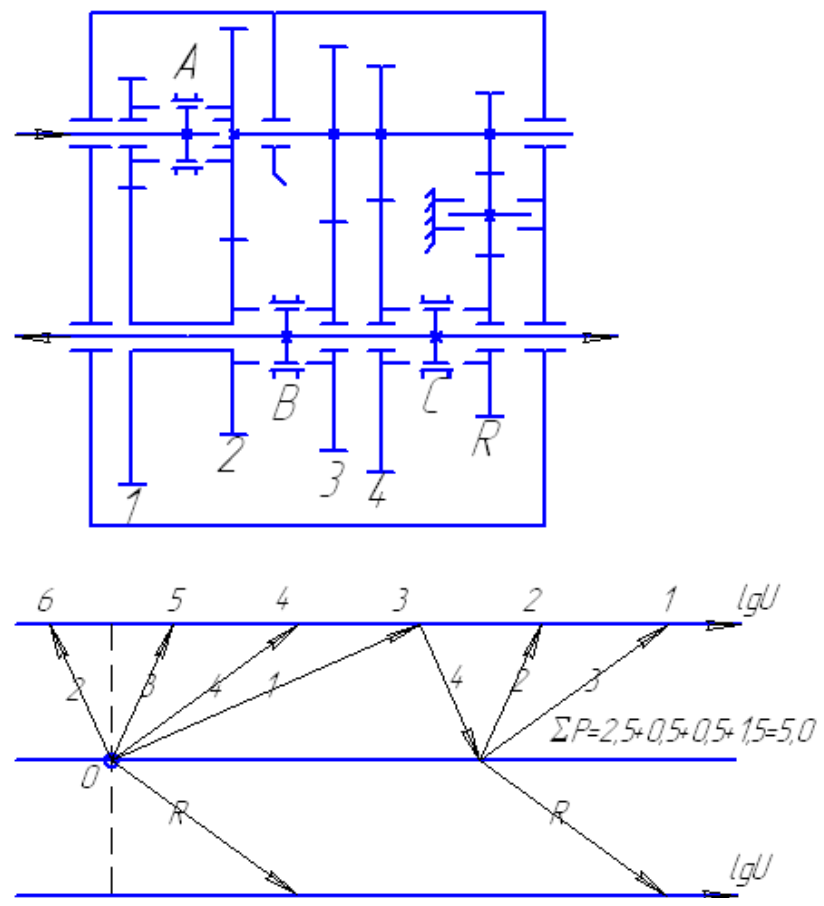

Figure 3: Kinematic flowchart and ray path diagram of two-shaft six-speed IGB

Based on the obtained equation, let us calculate variables of statistically average GB (Fig. 2):

$$
\begin{aligned}
& U_{1}=4.721 e^{-0.335}=3.377 ; \lg U_{1}=0.529 ; U_{2}=4.721 e^{-0.335 \cdot 2}=2.416 ; \lg U_{2}=0.383 ; \\
& U_{3}=4.721 e^{-0.335 \cdot 3}=1.728 ; \lg U_{3}=0.238 ; U_{4}=4.721 e^{-0.335 \cdot 4}=1.236 ; \lg U_{4}=0.092 ; \\
& U_{5}=4.721 e^{-0.335 \cdot 5}=0.884 ; \lg U_{5}=-0.053 ; U_{6}=4.721 e^{-0.335 \cdot 6}=0.633 ; \lg U_{6}=-0.199 ; \\
& D=\frac{U_{1}}{U_{6}}=\frac{3.377}{0.633}=5.33 ; \bar{q}=\sqrt[5]{D}=\sqrt[5]{5.33}=1.397 ; \lg \bar{q}=0.145 .
\end{aligned}
$$

Figure 2 shows kinematic flowchart of statistically average two-shaft six-speed GB and ray path diagram illustrating its operation. Horizontal scales of the ray path diagram show the gear ratio in logarithmic form. The torque input into GB (primary shaft) is denoted as point 0 on the middle horizontal line. This is the initial point of rays denoted by numbers corresponding to gear pairs. Rightward inclination of the ray indicates at reducing gear; the higher is the inclination, the higher is the gear ratio of gear pair. Leftward inclination of the ray indicates at increasing mode of gear pair. For instance, $U_{1}=3.377 ; \lg U_{1} \approx 0.53$ (see outlet of ray 1 in Fig. 2 below).

\section{2 Comparison of efficiencies of transmissions}

In order to compare efficiency of transmission designs, it is possible to apply relative evaluations $[1,2]$.
The ratio of forward gears to number of gears executing these speeds is the coefficient of intensity of gear use: Ki. The higher is the $\mathrm{Ki}$, the more intensively the gears are used upon various speeds and the lower is the longitudinal size of GB. Statistically average six-speed GB has 12 forward gears. The gears are used with insufficient efficiency: $\mathrm{Ki}=6 / 12=0.5$. IGB has $\mathrm{Ki}$ by 1.5 times higher: $\mathrm{Ki}=6 / 8=0.75$. The ratio of number of forward gears to the sum of intervals of gear pairs $\left(\sum \mathrm{P}\right.$ is the cumulative reduction) characterizes operation reasonability of gears and is estimated by the reduction coefficient $\mathrm{Kr}$. The lower is the cumulative reduction, the more efficient is the gear operation, the higher is the $\mathrm{Kr}$ and the lower is the lateral size of assembly. Let us calculate $\sum \mathrm{P}$ of statistically average GB:

$$
\begin{aligned}
& P_{1}=\frac{\lg U_{1}}{\lg \bar{q}}=\frac{0.529}{0.145}=3.65 ; P_{2}=\frac{\lg U_{2}}{\lg \bar{q}}=\frac{0.383}{0.145}=2.84 ; P_{3}=\frac{\lg U_{3}}{\lg \bar{q}}=\frac{0.238}{0.145}=1.64 ; \\
& P_{4}=\frac{\lg U_{4}}{\lg \bar{q}}=\frac{0.092}{0.145}=0.63 ; P_{5}=\frac{\lg U_{5}}{\lg \bar{q}}=\left|\frac{0.053}{0.145}\right|=0.37 ; P_{6}=\frac{\lg U_{6}}{\lg \bar{q}}=\left|\frac{0.199}{0.145}\right|=1.37 ; \\
& \sum P=P_{1}+P_{2}+P_{3}+P_{4}+P_{5}+P_{6}=3.65+2.84+1.64+0.63+0.37+1.37=10.3
\end{aligned}
$$

(see Fig. 2, middle horizontal line). 
For statistically average six-speed $\mathrm{GB}, \mathrm{Kr}=6 / 10.3=0.58$, and for IGB, $\mathrm{Kr}=6 / 5=1.2$, which is significantly higher. The sum of the coefficient of gear operation intensity Ki and the reduction coefficient $\mathrm{Kr}$ characterizes the operation efficiency of GB gears and is estimated by the coefficient of efficiency $\mathrm{Ke}[1,2]$. For statistically average GB, $\mathrm{Ke}=0.5+$ $0.58=1.08$ is moderate; for IGB, $\mathrm{Ke}=0.75+1.2=1.95$, that is, by about two times higher.

Efficiency of GB arrangement can be significantly improved by loose arrangement of gears on shafts, which facilitates development of IGB (improved GB). An important advantage of IGB is multiple contact at lower speeds, and with significant range of IGB, it is possible to obtain low gear ratios in gear pairs and to decrease inter-axial distance and GB sizes $[1,2]$. The flowchart of six-speed IGB and its ray path diagram are illustrated in Fig. 3. Maximum gear ratio (2.5 intervals) is in the first gear pair against 3.65 intervals of previous GB, slightly lower (1.5 intervals) is the gear ratio in the fourth pair, the ratio in the third and the second gear pairs is even lower ( 0.5 intervals).

\section{RESULT AND DISCUSSION}

\subsection{Operation of improved six-speed GB}

If we assume that $\mathrm{D}=8$, then $\mathrm{q}=1.516$; and $\lg \mathrm{q}=0.181$. The gear ratio of the first pair in this case is $\mathrm{U}_{3}=1.516^{2.5}=2.83 ; \mathrm{lg}$ $2.83=0.45$. Upon torque transfer by this gear pair, the third speed is provided, the torque from primary shaft by the clutch A in the left position is transferred to the first gear pair, then via the module and the clutch $\mathrm{B}$ in the left position - to the secondary shaft; the clutch $\mathrm{C}$ is in neutral position.

The fourth speed is provided by engagement of the fourth gear pair. From the primary shaft via the clutch $\mathrm{A}$ in the right position torque is transferred to the next coaxial shaft, then, via the fourth gear pair and via the clutch $\mathrm{C}$ in the left position - to the secondary shaft, the clutch B is in neutral position. The gear ratio of this speed is $U_{4}=1.516^{1.5}=1.87$.

The fifth speed is provided by the third gear pair; herewith, the clutch $\mathrm{C}$ is shifted into neutral position, and the clutch $\mathrm{B}$ - to the right position. The gear ratio of this speed is $\mathrm{U}_{5}=1.516^{0.5}=1.23$.

The sixth speed with $\mathrm{U}_{6}=1 / 1.23=0.81$ is achieved by operation of the second gear pair upon shifting of the clutch B to the left position.

The four top speeds, more frequently applied, operate with high efficiency due to one-pair contact. Two low speeds are provided by three-pair contacts: the second speed (1-2-3) is with $\mathrm{U}_{2}=1.516^{3.5}=4.29$; the clutches $\mathrm{A}$ and $\mathrm{C}$ are in the left position, and the clutch $\mathrm{B}$ is in the right position; if the clutch $B$ is shifted to the left position, then we obtain the first speed $(1-2-4)$ with $U_{1}=1.516^{4.5}=6.5$. The mentioned gear ratios of
IGB are in agreement with the equation $y=9.8984 e^{-0.4171 x}$ (Fig. $1)$ :

$y=9.8984 e^{-0.4171}=6.5 ; y=9.8984 e^{-0.4171 \cdot 2}=4.3 ;$

$y=9.8984 e^{-0.4171 \cdot 3}=2.8 ;$

$y=9.8984 e^{-0.4171 \cdot 4}=1.9 ; y=9.8984 e^{-0.4171 \cdot 5}=4.3 ; y=$ $9.8984 e^{-0.4171 \cdot 6}=4.3$;

$\mathrm{D}=\mathrm{U}_{1} / \mathrm{U}_{6}=6.5 / 0.81=8.0$.

\subsection{Technical and economical evaluation of the improved GB}

The flowchart of six-speed IGB illustrated in Fig. 3 makes it possible to create transmission designs of low metal intensity with good operation properties: convenient gear shifting due to low intervals $(\mathrm{q}=1.5-1.6)$ and wide range ( $\mathrm{D}=8-16$ ). With the aim of comparison: statistically average six-speed $\mathrm{GB}$ of conventional arrangement is $\mathrm{D}=5.33$.

Upon conventional arrangement of GB illustrated in Fig. 2, each gear pair is used only for one speed, 12 gears are required for six speeds, the coefficient of intensity of gear is $\mathrm{Ki}=6 / 12$ $=0.5$. Loose arrangement of gears on shafts applied for the design depicted in Fig. 3 is characterized by wide potentials, six speeds require only 8 gears, $\mathrm{Ki}=6 / 8=0.75$. Each additional gear pair doubles the number of speeds, 10 gears provide 12 speeds, $\mathrm{Ki}=12 / 10=1.2$; six gear pairs used in Fig. 1 for six speeds can provide 24 speeds, $\mathrm{Ki}=24 / 12=2$. If the design of considered six-speed IGB is slightly modified and some reverse gears are replaced with a pair of forward gears then we obtain eight-speed IGB $(\mathrm{Ki}=8 / 8=1)$. Sixteen-speed two-shaft IGB is in fact an eight-speed GB with added gear pair and dual driving clutch $(\mathrm{Ki}=16 / 10=1.6)$. Similarly, it is possible to obtain 32 speeds, and the coefficient of intensity of gear usage increases to $\mathrm{Ki}=32 / 12=2.67[1,2]$.

Therefore, application of IGB expands operability of land vehicles due to increase in the coefficient of intensity of gear usage. This provides possibility to develop transmissions of small sizes and low metal intensity.

It is necessary to develop competitive compact designs of GB with moderate metal intensity. Loose arrangement of gears on shafts makes it possible to improve efficiency of gear usage and assembly arrangement.

IGB is well compatible with double clutches. Double clutch enables gear shifting nearly without loss of torque. Figure 4 [3] illustrates the flowchart of six-speed IGB with two clutches and ray path diagram describing its operation [4]. 

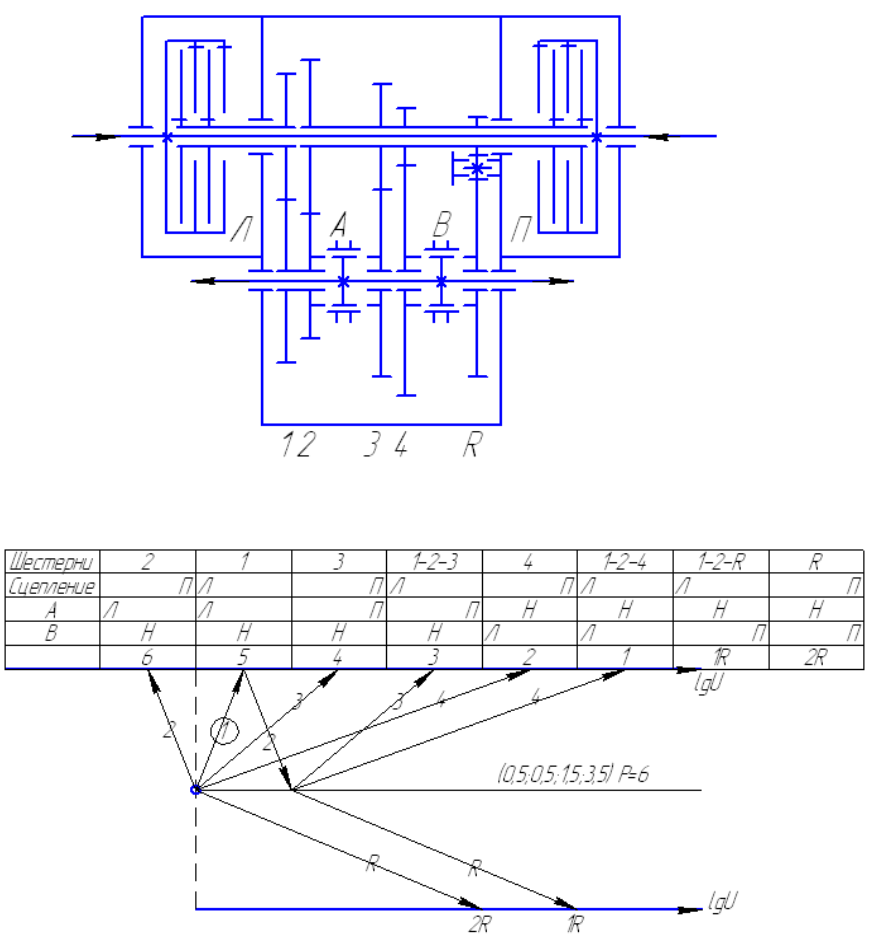

Figure 4: Kinematic flowchart and ray path diagram of two-shaft six-speed IGB with two clutches [5]

\section{CONCLUSION}

Tyumen Industrial University is the holder of the main set of patents protecting the method of gear loose assembling on shafts. The activities aimed at further improvement of transmission design meeting modern requirements are under ways.

\section{REFERENCES}

1. V.I. Nekrasov. Kompaktnye mnogostupenchatye korobki peredach [Compact multispeed gearboxes]. Avtomobil'naya promyshlennost', Vol. 5, pp.16-20, 1995.

2. V.I. Nekrasov. Kompaktnye val'nye korobki peredach [Compact shaft gearboxes]. Avtomobilnaya promyshlennost', Vol. 10, pp.13-16, 1999.

3. A.V. Astakhova, V.I. Nekrasov. Korobki peredach s dvoinym stsepleniem [Gearboxes with double clutches]. Collection of articles: Operational issues of transportation systems, Tyumen, pp.12-16, 2008.

4. V.I. Nekrasov. Optimization of main parameters of gearboxes with three gear trains. ARPN Journal of Engineering and Applied Sciences, Vol. 12(11), pp. 3526-3531, June 2017.

5. R.A. Ziganshin. Six-speed power gearboxes. International Journal of Mechanical Engi-neering and Technology, Vol. 8(10), pp. 401-409, October 2017. 